\title{
Massive hemobilia from a ruptured hepatic artery aneurysm detected by endoscopic ultrasound (EUS) and successfully treated
}

Massive hemobilia from a ruptured hepatic artery aneurysm (HAA) is a serious complication and difficult to treat. The majority of cases are the result of accidental or iatrogenic trauma. Other causes are inflammatory, tumor bleeding, vascular disorders, and cholecystolithiasis [1-3]. Treatment of a specific aneurysm depends on its location and the regional vascular anatomy. Therapeutic options include embolization of the aneurysm, stenting across the parent vessel, and embolization of the common hepatic artery or open surgical repair, with or without reconstruction $[4,5]$. We reported a case of ruptured HAA with massive hemobilia that was first diagnosed by endoscopic ultrasonography (EUS) and treated successfully by percutaneous ultrasound-guided glue injection directly into the HAA.

A 55-year-old man presented with abdominal pain and jaundice without history of previous abdominal surgery or trauma. Magnetic resonance imaging (MRI) showed a soft tissue mass within a large cystic lesion at the pancreatic head (৫ Fig. 1).

The patient underwent endoscopic retrograde cholangiopancreatography (ERCP) with plastic stent placement and was referred to our institution for endoscopic ultrasound (EUS) evaluation. On EUS, echoultrasonography with color Doppler revealed a large cystic lesion with detectable to-and-fro color flow, arising from the common hepatic artery ( Fig. 2 , - Video 1).

A large HAA, which was protruding through the arterial wall, was diagnosed and therefore open surgical management was the first treatment consideration. After 1 week the patient developed massive upper gastrointestinal bleeding. Emergency angiography with embolization was carried out but failed to completely stop the bleeding ( $\bullet$ Fig. 3 ).

\section{Video 1}

Radial echoendosonography with color Doppler demonstrating a large, irregular, cystic mass with to-and-fro flow from the main hepatic artery.

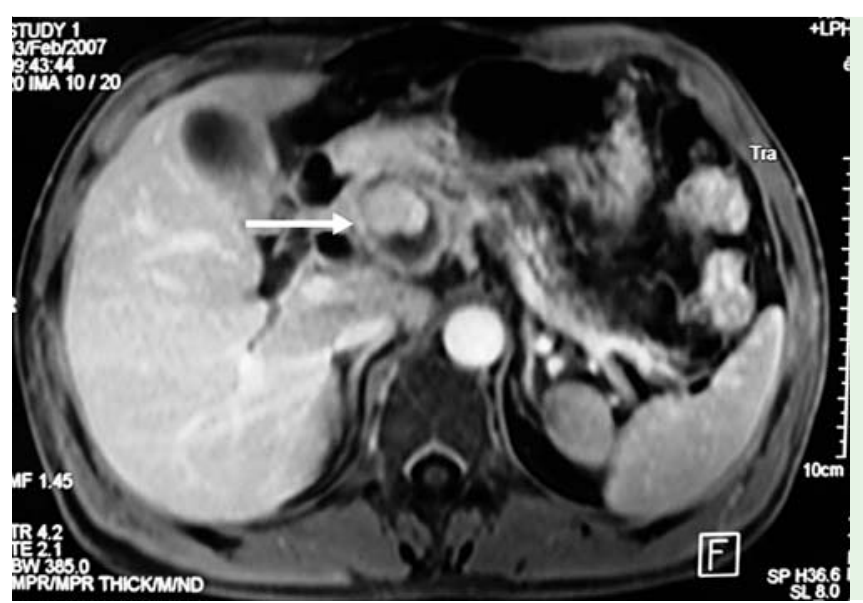

Fig. 1 Magnetic resonance image showing a large cystic lesion containing soft tissue (arrow), at the pancreatic head.

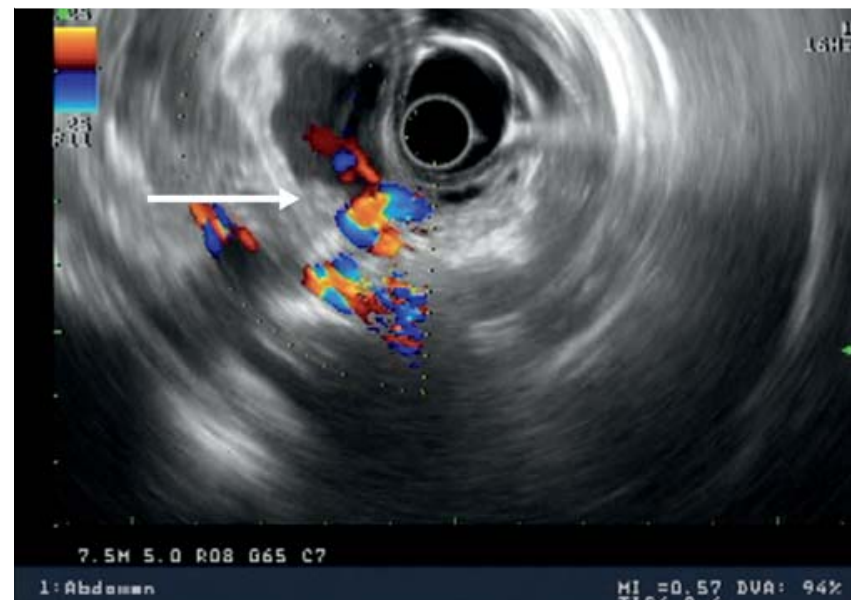

Fig. 2 Radial echoultrasonography with color Doppler showing typical to-and-fro flow in a large cystic lesion (arrow) communicating with the hepatic artery.

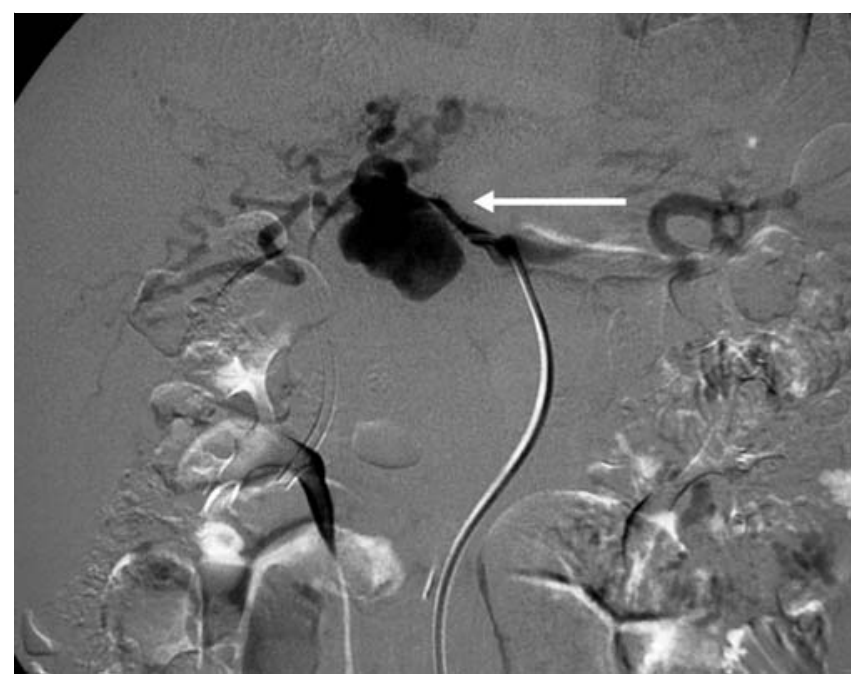

Fig. 3 Angiogram showing the hepatic artery aneurysm (arrow) (large size, $4 \times 5 \mathrm{~cm}$ ). 

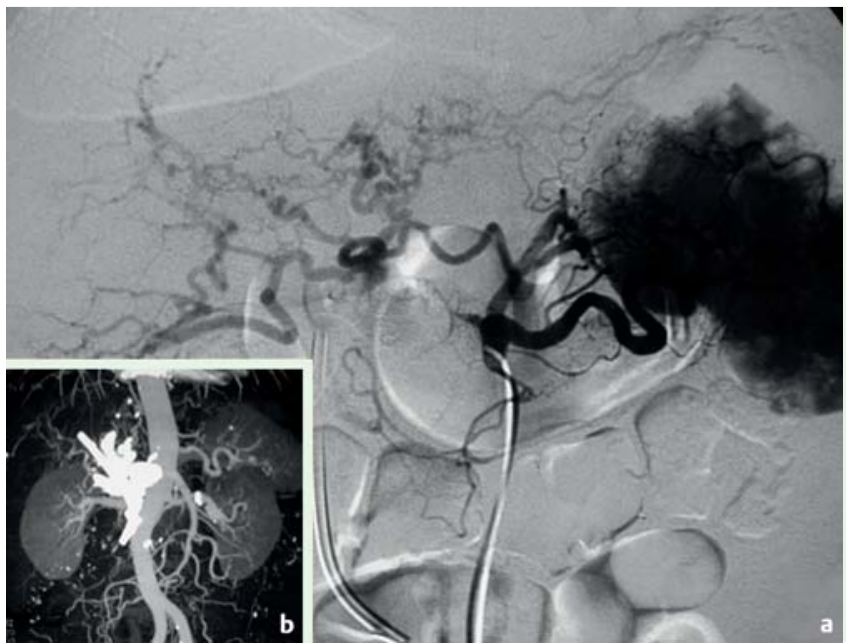

Fig. 4 a Angiogram taken after glue injection demonstrating complete occlusion of the hepatic artery aneurysm with collateral circulation from the celiac trunk to the hepatic artery. b Computed tomography (CT) scan at 3 months after injection showing the staining due to the residual glue inside the lesion.
A percutaneous injection of Histoacryl was given directly into the aneurysm (๑ Fig. 4).

In the 1-month follow-up period, the patient's liver function normalized and the plastic stent was endoscopically removed. At the 2-year follow-up he remained in a good condition with no signs of recurrent bleeding or liver infarction.

\section{Competing interests: None}

Endoscopy_UCTN_Code_CCL_1AF_2AF_3AZ

\section{References}

1 Bloechle C, Izbicki JR, Rashed MY. Hemobilia: presentation, diagnosis, and management. Am J Gastroenterol 1994; 89: 1537-1540

2 Abbas MA, Fowl RJ, Stone WM et al. Hepatic artery aneurysm: factors that predict complications. J Vasc Surg 2003; 38: 41 - 45

3 Messina LM, Shanley CJ. Visceral artery aneurysms. Surg Clin North Am 1997; 77: $425-442$

4 Tulsyan N, Kashyap VS, Greenberg RK et al. The endovascular management of visceral artery aneurysms and pseudoaneurysms. J Vasc Surg 2007; 45: 276 - 283

5 Doughter MJ, Gloviczki P, Cheery KJ et al. Hepatic artery aneurysms: evaluation and current management. J Vasc Surg 2003; 12: $178-184$

Bibliography

DOI $10.1055 / \mathrm{s}-0030-1255940$

Endoscopy 2010; 42: E340 - E341

(c) Georg Thieme Verlag KG Stuttgart · New York . ISSN 0013-726X

Corresponding author

T. Akaraviputh

Minimally Invasive Surgery Center

Division of General Surgery

Department of Surgery

Faculty of Medicine Siriraj Hospital

Mahidol University

Bangkok 10700

Thailand

Fax: +66-24121370

sitak@mahidol.ac.th 